\title{
Frequency-Tuned Distribution of Inhibition in the Dentate Gyrus
}

\author{
Laura A. Ewell and Mathew V. Jones \\ Department of Physiology, University of Wisconsin, Madison, Wisconsin 53706
}

Granule cells (GCs) of the dentate gyrus use sparse encoding to perform redundancy reduction, pattern separation, and novelty detection. One likely candidate mechanism to enforce low spiking activity is feedforward inhibition, in which the cortical excitatory drive from the perforant path (PP) recruits GABAergic interneurons that then inhibit GCs. Little is known, however, about how PP drive is balanced between GCs versus inhibitory neurons. In simultaneous recordings of GCs and fast-spiking (FS) interneurons from C57BL/6 mice, we find that focal PP stimulation preferentially recruits spiking in FS interneurons over GCs, because GCs require a larger excitatory synaptic current density to reach spike threshold. Blocking inhibition reversed this relationship, revealing a stronger intrinsic coupling between the PP and GCs versus FS interneurons and showing that inhibition can sparsify the output of the dentate gyrus by tightly regulating GC spike probability. Moreover, this regulation is dynamic, because the spiking profile of FS interneurons was frequency tuned, displaying bursting behavior in response to PP stimulation near theta rhythm frequency $(\sim 10 \mathrm{~Hz})$. The later spikes in the bursts were part of the feedback inhibitory pathway because they were driven by late EPSCs, were blocked by an inhibitor of synaptic output from GCs, and shared the same frequency dependence as GC spiking. Therefore, the temporal content of signals arriving via the PP determines whether a FS interneuron participates in only feedforward (one spike) or both feedforward and feedback (burst) inhibition.

\section{Introduction}

The theory of autoassociative encoding of spatial and episodic memories in the hippocampus requires that patterns of neural activity be stored through strengthening of interconnections between excitatory neurons (Marr, 1971; Rolls, 2007). However, such connections also make the hippocampus susceptible to runaway excitation and seizures (Lothman et al., 1991). To protect against this propensity toward hyperexcitability, it has been hypothesized that the dentate gyrus acts as a gate or filter at the front end of hippocampal processing. (Heinemann et al., 1992).

In regard to memory encoding, the filtering property of the dentate gyrus enables this region to perform a more complicated function termed "pattern separation" (Leutgeb and Moser, 2007). Several computational models suggest that a finite network of neurons storing retrievable patterns of activity is susceptible to destructive interference that comes about when several patterns share too many common neurons and are thus difficult to activate individually without recruiting other patterns (O'Reilly and McClelland, 1994). To maintain the integrity of individual patterns in the hippocampal network, recent experimental evidence suggests that granule cells (GCs) in the dentate gyrus encode a sparse representation of their perforant path input, minimizing overlap between patterns (Leutgeb et al., 2007). There are at least two ways the dentate gyrus may achieve this.

Received April 12, 2010; revised July 28, 2010; accepted Aug. 3, 2010.

L.A.E. was funded by the Epilepsy Foundation through the generous support of the American Epilepsy Society.

Correspondence should be addressed to Laura A. Ewell, Department of Physiology, University of Wisconsin

Madison, Service Memorial Institute 127, 1300 University Avenue, Madison, WI 53706.E-mail: lastenton@wisc.edu. DOI:10.1523/JNEUROSCI.1854-10.2010

Copyright $\odot 2010$ the authors $\quad 0270-6474 / 10 / 3012597-11 \$ 15.00 / 0$
First, the perforant path inputs could selectively target unique groups of GCs (the principal excitatory cells), and thus individual patterns would be segregated to mutually exclusive groups of GCs. In this case, the coding would be sparse across space. Second, the dentate gyrus could transform the patterns, emphasizing only the necessary or distinguishing components. Such a transformation would presumably be a network phenomenon involving both excitatory and inhibitory neurons. Indeed, several classes of hilar interneurons are more easily driven by stimulation of the perforant path than are dentate GCs, which constitute the output of dentate gyrus (Scharfman, 1991). Furthermore, recent computational evidence suggests that the activity of hilar interneurons is key for pattern separation and gating against seizures (Myers and Scharfman, 2009). Still, little is known about the differential flow of perforant path input onto multiple cell types in the dentate gyrus and about the physiology that underlies the sensitivity of hilar interneurons and the insensitivity of GCs to the perforant path (Scharfman, 1991). We show that the lateral and medial perforant path inputs, which arise from the lateral and medial entorhinal cortex, respectively (Witter, 1993), both preferentially recruit fast-spiking (FS) inhibitory interneurons compared with GCs and that this preference primarily relies on a difference in the strength of the feedforward inhibition in the two cell types and a stronger drive onto FS interneurons rather than on the intrinsic properties of the cells. The preferential recruitment of FS interneurons upon perforant path stimulation also shows frequency-dependent bursting that arises from the differential timing of feedforward and feedback drives, suggesting that only certain frequencies activate GCs that mediate both the feedback drive and the output of the dentate gyrus. 


\section{Materials and Methods}

Electrophysiology. Transverse hippocampal slices $(400 \mu \mathrm{m})$ were prepared from the brains of C57 black 6 (C57BL/6) male mice 12-21 d old. All procedures were approved by the University of Wisconsin Institutional Animal Care and Use Committee. Mice were anesthetized with halothane or isoflurane, decapitated, and the brain was removed quickly and placed in ice-cold cutting solution containing (in mM) $125 \mathrm{NaCl}, 25$ $\mathrm{NaHCO}_{3}, 2.5 \mathrm{KCl}, 1.25 \mathrm{NaH}_{2} \mathrm{PO}_{4}, 0.5 \mathrm{CaCl}_{2}, 3.3 \mathrm{MgCl}_{2}$, and 70 sucrose bubbled with $95 \% \mathrm{O}_{2}$ and $5 \% \mathrm{CO}_{2}$. Slices were cut using a vibratome (Leica VT 1000S) and placed in an incubation chamber in a mixture (1:1) of cutting solution and standard artificial CSF (ACSF) containing (in mм) $125 \mathrm{NaCl}, 25 \mathrm{NaHCO}_{3}, 2.5 \mathrm{KCl}, 1.25 \mathrm{NaH}_{2} \mathrm{PO}_{4}, 2 \mathrm{CaCl}_{2}, 1 \mathrm{MgCl}_{2}$, and $25 \mathrm{D}$-glucose at $35^{\circ} \mathrm{C}$ for $30 \mathrm{~min}$ before being used for recordings. All recordings were done in standard ACSF. Whole-cell patch-clamp or cellattached recordings were made from dentate gyrus GCs and FS interneurons and visualized using an upright microscope (Axioskop FS2, Zeiss) with infrared differential interference contrast (IR-DIC) optics. Patch pipettes pulled from thin-walled borosilicate glass (World Precision Instruments) had a resistance of 3-5 M $\Omega$ when filled with intracellular solution containing (in mM) $140 \mathrm{~K}$-gluconate, 10 EGTA, 10 HEPES, 20 phosphocreatine, $2 \mathrm{Mg}_{2} \mathrm{ATP}$, and $0.3 \mathrm{NaGTP}$, pH 7.3 (310 mOsm). Recordings were made at room $\left(22-25^{\circ} \mathrm{C}\right)$ or physiological temperature $\left(33-35^{\circ} \mathrm{C}\right)$ as noted in the text using one or two Axopatch $200 \mathrm{~B}$ amplifiers (Molecular Devices) and filtered at $5 \mathrm{kHz}$ using a 4-pole Bessel filter and digitized at $10 \mathrm{kHz}$ using a Digidata $1320 \mathrm{~A}$ analog-digital interface (Molecular Devices). Data were acquired to a Macintosh G4 (Apple Computer) using Axograph X, version 1.0.7 (Molecular Devices). For cell-attached recordings, a G $\Omega$ seal was formed by applying negative pressure to the patch pipette placed on the surface of a GC or interneuron. The patch was voltage clamped at $0 \mathrm{mV}$, and perforant path-recruited action currents with an early fast negative deflection followed by a slow positive deflection were recorded.

Stimulation pipettes were pulled from double-barrel borosilicate theta glass ( $<5 \mu \mathrm{m}$ tip diameter, Harvard Apparatus) and had a resistance between $800 \mathrm{k} \Omega$ and $2 \mathrm{M} \Omega$ when filled with extracellular solution. To electrically stimulate the perforant path, the bipolar theta pipette was connected to a constant current stimulus isolator used to generate $0.1-10$ $\mathrm{mA}$ pulses, $100 \mu \mathrm{s}$ in duration. The theta pipette was placed in the outer molecular layer or middle molecular layer as noted. To chemically stimulate the perforant path, a patch pipette was filled with $100 \mathrm{~mm} \mathrm{KCl}$, and puffs $(5 \times 200 \mathrm{~ms}, 300 \mathrm{~ms}$ interpuff interval, $<10 \mathrm{psi})$ were delivered to the far side of the hippocampal fissure across from the molecular layer of the dentate gyrus (see Fig. 1).

Data analysis and statistics. Data analysis was performed in either Axograph X, version 1.0.7 (Axograph Scientific) or Matlab 7.1 (Mathworks). Statistical analysis was performed in Prism4 (Graphpad Software). For comparisons between two groups of data, Student's two-tailed $t$ tests (paired or unpaired as appropriate) were performed. For comparisons between three or more groups, one-way ANOVAs were performed (with repeated measures if there was pairing). Dunnett's multiple comparison test was applied for post hoc analysis. For one case, an $F$ test was used to test significance between two sets of data fit to separate exponential functions (see Fig. 4C). Significance between the two curves was determined with a $F$ value comparing the fit for each dataset separately to the fit of the combined datasets (Motulsky and Ransnas, 1987). All values are reported as mean \pm SEM or interquartile range unless otherwise noted.

Input-output relationships. To construct input-output relationships, the responses of FS interneurons and GCs to 20 pulse, $10 \mathrm{~Hz}$ stimulus trains delivered to the perforant path were analyzed. For voltage-clamp responses, the peak current was measured in the $20 \mathrm{~ms}$ window following each stimulus in the train. Peak currents were averaged across trials, so each dataset yielded 20 average peak currents (one for each stimulus in the train). For current-clamp responses, a threshold detection of -20 $\mathrm{mV}$ determined whether a spike was triggered for each stimulus in the train. Counting the number of spikes triggered per stimulus (either 1 or 0 ) and dividing by the number of trials yielded the spike probability, $p$ (spike), associated with each stimulus in the train. Peak currents were normalized by cell capacitance because of the difference in size between
GCs and FS interneurons, yielding current densities. Current densities were plotted against $p$ (spike) and the relationship was empirically fit with a sigmoid: $[\tanh ((x$-midpoint $) /$ slope $) / 2+1 / 2]$. Midpoints of these relationships were compared between FS interneurons and GCs with an unpaired two-tailed Student's $t$ test.

Synaptic event detection. To compare the responses of GCs and FS interneurons to chemical (puff) stimulation of the perforant path, IPSCs and EPSCs were detected using the AxographX, version 1.07 templatematching algorithm. The synaptic templates used for event detection were unique to each cell and determined on a first pass using a generic template. IPSC templates were $30 \mathrm{~ms}$ long and had rise time constants of $1.6 \pm 0.1 \mathrm{~ms}$ and decay time constants of $12.9 \pm 0.5 \mathrm{~ms}$. EPSC templates were $15 \mathrm{~ms}$ long and had rise time constants of $0.5 \pm 0.06 \mathrm{~ms}$ and decay time constants of $4.6 \pm 0.3 \mathrm{~ms}$. For both IPSC and EPSC templates, the template is shorter than the time course of IPSCs/EPSCs because we wanted to capture overlapping events; therefore, the decay time constants given above reflect the fast component of decay. For both templates, the threshold for detection was $4 \times$ the SD of the noise. Mean rates were determined by dividing the number of events detected per trial by the length of the trial $(20 \mathrm{~s})$. Significance was determined with the twotailed Student's $t$ test (paired or unpaired as stated in the text).

Burst analysis. Spikes were detected at a threshold of $0 \mathrm{mV}$. Bursts were defined as groups of spikes separated by $<20 \mathrm{~ms}$. The average number of spikes per burst was determined for several stimulus frequencies, and significance was determined with a one-way ANOVA with repeated measures and Dunnett's multiple comparison test. To block late spikes in a burst, a patch pipette was filled with $5 \mu \mathrm{M}\left(2 S, 2^{\prime} R, 3^{\prime} R\right)-2-\left(2^{\prime}, 3^{\prime}\right.$-dicarboxycyclopropyl)glycine (DCG -IV), which was puffed locally on the hilar side of the GC layer $(3 \times 500 \mathrm{~ms}, 600 \mathrm{~ms}$ interpuff intervals, $<10 \mathrm{psi})$ before each electrical stimulus train. The burst probabilities for each episode (number of bursts per episode /number of stimuli per episode) were averaged across episodes for each condition (control, drug, wash).

\section{Results}

\section{Perforant path preferentially recruits inhibitory cells versus excitatory cells}

To study perforant path recruitment of excitatory and inhibitory cells in the dentate gyrus, we recorded from excitatory GCs and inhibitory FS interneurons (Fig. 1A). Both cell types were identified based on morphology under IR-DIC optics and their different responses to current steps injected into their somas. Cell parameters given in the following section are presented as interquartile ranges and mean \pm SEM and are pooled between room temperature and physiological temperature. FS interneurons $(n=61)$ had resting membrane potentials of -60 to $-70 \mathrm{mV}$ $(-65 \pm 0.9 \mathrm{mV})$, firing rates of $62-111 \mathrm{~Hz}(90 \pm 6 \mathrm{~Hz})$ for $500 \mathrm{pA}$ somatic current injections (Fig. $1 \mathrm{~B}$ ), series resistances of $4.8-7.4$ $\mathrm{M} \Omega(6.4 \pm 0.2 \mathrm{M} \Omega)$, input resistances of $65-136 \mathrm{M} \Omega(113 \pm 8$ $\mathrm{M} \Omega)$, and capacitances of $25-33 \mathrm{pF}(29 \pm 0.9 \mathrm{pF})$. Note that firing rates were significantly higher at physiological temperature for FS interneurons $(109 \pm 10$ versus $73 \pm 4 \mathrm{~Hz}, p \leq 0.001$, unpaired $t$ test). The action potentials showed little to no accommodation to currents steps of $500 \mathrm{pA}$, had a large afterhyperpolarization following individual action potentials, and were brief $(<1.0 \mathrm{~ms}$ total duration). Under IR-DIC optics, the somas of FS interneurons were large ( $\sim 20 \mu \mathrm{m}$ diameter), round or oval with prominently visible dendrites extending from the cell body, and located adjacent to the granule cell layer on both the hilar and molecular layer sides. Based on these criteria published previously by ourselves (Harney and Jones, 2002), we expect that the population is comprised primarily of basket cells and, to a lesser extent, axoaxonic cells. GCs $(n=57)$ had resting membrane potentials of -55 to $-73 \mathrm{mV}(-63.5 \pm 1.5 \mathrm{mV})$, firing rates of $10-20 \mathrm{~Hz}(14.1 \pm 0.9) \mathrm{Hz}$ for $50 \mathrm{pA}$ somatic current injections (Fig. $1 B$ ), series resistances of $6.8-8.7 \mathrm{M} \Omega(7.8 \pm 0.3 \mathrm{M} \Omega$ ), input resistances of $175-379 \mathrm{M} \Omega(325.8 \pm 36.7 \mathrm{M} \Omega)$, and capacitances 
A

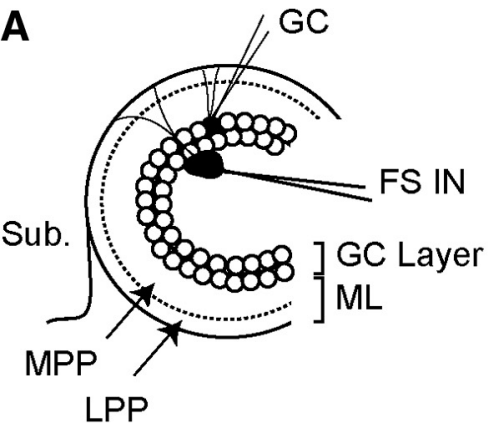

C
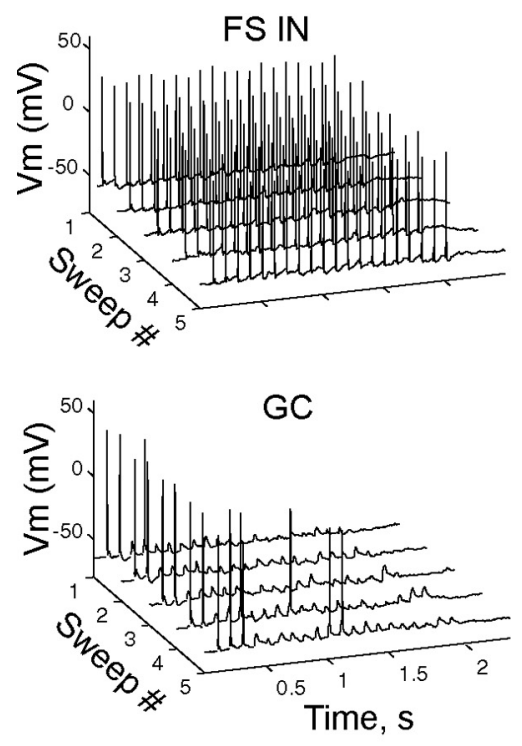

B

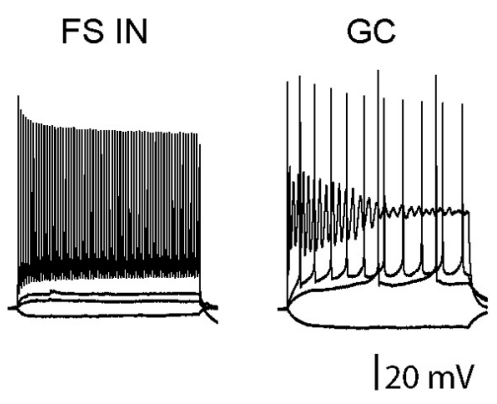

D
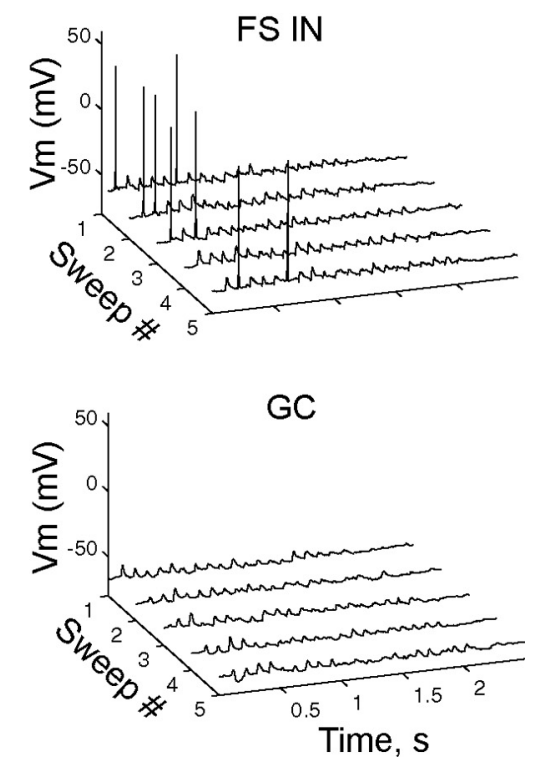

Figure 1. Perforant path stimulation preferentially recruits FS interneurons compared with GCs. $\boldsymbol{A}$, Schematic illustrating the experimental setup. Whole-cell recordings were made from a GC and FS interneuron (FS IN). For each experiment, the middle molecular layer (MML) and the outer molecular layer (OML) were stimulated. ML, Molecular layer; Sub., subiculum. $\boldsymbol{B}$, Currentclamp response of a FS IN and a GC to 1-s-long current steps of $-25,25,50$, and 500 pA. C, Current-clamp responses recorded simultaneously from a FS IN (top) and a GC (bottom) to a 20 pulse $10 \mathrm{~Hz}$ train delivered to the middle molecular layer. $\boldsymbol{D}$, The response of the same two cells as in $\mathbf{C}$, to outer molecular layer stimulation.

of $14-19 \mathrm{pF}(16.0 \pm 0.4 \mathrm{pF})$. In our hands the resting membrane potential of GCs are more depolarized compared with reports by others (Schmidt-Hieber et al., 2007); however, our observations are consistent with the finding that granule cells are more depolarized in juvenile rats (Liu et al., 2000).

Although several classes of inhibitory interneurons might receive perforant path inputs based on the distribution of their dendritic fields in the middle and outer molecular layer (Freund and Buzsaki, 1996), we focused on FS interneurons in particular because their membrane and synaptic properties have been well characterized previously (Geiger et al., 1997; Kraushaar and Jonas, 2000; Harney and Jones, 2002; Hu et al., 2010), they are known to be involved in both feedforward and feedback inhibition (Kneisler and Dingledine, 1995), and they are important for generation of oscillations associated with specific cognitive states (Bartos et al., 2002).

Previous studies have shown that perforant path stimulation preferentially recruits spiking in interneurons compared with GCs (Scharfman, 1991). To dissect the mechanism of this preferential recruitment, we stimulated either the outer molecular layer or the middle molecular layer with a small theta glass-stimulating electrode and simultaneously recorded responses from GCs and FS interneu- rons. Fibers of the lateral perforant path lie in the outer molecular layer, while fibers of the medial perforant path lie in the middle molecular layer (McNaughton and Barnes, 1977; McNaughton, 1980; Abraham and McNaughton, 1984; Witter, 2007). Such simultaneous recordings allowed us to deliver an identical stimulus to the two cell types and, therefore, differences in recruitment were not caused by difference in stimulus strength or location. Placing the stimulating electrode in the middle molecular layer and stimulating fibers there with a $10 \mathrm{~Hz}, 20$ pulse train preferentially recruited spikes in FS interneurons that fired on average $6.9 \pm$ 2.4 spikes per train, whereas GCs showed a weaker response and fired on average only $0.44 \pm 0.34$ spikes per train $(p \leq 0.02, n=$ 10 , paired $t$ test) (Fig. 1C). Simultaneous voltage-clamp recordings revealed that middle molecular layer-mediated EPSCs show strong depression for both cell types $\left[\mathrm{EPSC}_{20} / \mathrm{EPSC}_{1}, \mathrm{GCs}=0.4 \pm 0.04(n=5)\right.$; $\mathrm{FS}$ interneurons $=0.37 \pm 0.04]$. Placing the stimulating electrode in the outer molecular layer and stimulating the fibers there did not reveal a difference in spike recruitment ( $p \leq 0.58, n=6$, paired $t$ test) (Fig. $1 D$ ). FS interneurons fired on average $2.6 \pm 2.1$ spikes per train $(n=6)$, and GCs fired on average $1.1 \pm 0.75$ spikes per train $(n=6)$. Simultaneous voltage-clamp recordings revealed that outer molecular layer-mediated EPSCs also show strong depression for both cell types $\left[\mathrm{EPSC}_{20} / \mathrm{EPSC}_{1}, \mathrm{GCs}=0.36 \pm\right.$ $0.02(n=5) ; \mathrm{FS}$ interneurons $=0.53 \pm 0.11$ $(n=5)]$. These simultaneous recordings suggest that signals arriving via perforant path fibers in the middle molecular layer recruit more activity in FS interneurons compared with GCs.

Input-output relationships reveal that FS interneurons are more tightly coupled to perforant path inputs than GCs

Several explanations could account for the preferential recruitment of FS interneurons by the perforant path. The synapses might be stronger or more numerous onto FS interneurons compared with GCs, FS interneuron spike threshold might be lower than GC spike threshold, or there might be differences in the strength of synaptic coupling between the perforant path and FS interneurons compared with GCs. To begin to distinguish between these possibilities, we constructed input-output relationships to determine the strength of the synaptic drive required to recruit spikes in the two cell types. Voltage responses (spikes) were recorded in current-clamp for a $10 \mathrm{~Hz}$ stimulus train and then, without changing the stimulator location or intensity, current responses (excitatory postsynaptic currents, EPSCs) to the same stimulus train were recorded in voltage-clamp (Fig. $2 A$ ). In this manner, average EPSCs were paired with their corresponding spike probabilities. For each cell type, the outer and middle molecular layers were stimulated independently to construct input-output relationships for both pathways. Currents were nor- 
malized to the capacitance estimated by fitting the passive current transients evoked by a $5 \mathrm{mV}$ voltage step.

The midpoints (EPSC current density where the spike probability is 0.5 ) of these relationships represent the strength of synaptic coupling between the perforant path input and the spike output. Curves with low midpoints have strong coupling because less current density is required to drive spikes. Both the outer molecular layer fibers and middle molecular layer fibers had a stronger coupling to FS interneurons than to GCs. For the middle molecular layer stimulation, midpoints for FS interneurons were $7.3 \pm 0.61$ $\mathrm{pA} / \mathrm{pF}(207 \pm 22 \mathrm{pA})$ whereas the midpoints of GCs were $19 \pm 2.2 \mathrm{pA} / \mathrm{pF}(292 \pm$ $44 \mathrm{pA})(p \leq 0.0007, n=5, n=5$, unpaired $t$ test) (Fig. $2 B$, left). For the outer molecular layer stimulation, midpoints for FS interneurons were $8.7 \pm 0.67$ $\mathrm{pA} / \mathrm{pF}(248 \pm 25 \mathrm{pA})$ whereas the midpoints for GCs were $14 \pm 2.0 \mathrm{pA} / \mathrm{pF}$ $(201 \pm 28 \mathrm{pA})(p \leq 0.046, n=5, n=5$, unpaired $t$ test) (Fig. $2 B$, right).

In FS interneurons, less current density was required to drive spiking for middle molecular layer stimulation compared with outer molecular layer stimulation ( $p \leq 0.02, n=5$, unpaired $t$ test). To understand how currents recruited via middle versus outer molecular layer stimulation differentially affect the membrane potential of FS interneurons, we reasoned that the voltage trajectory is proportional to the integral of current and thus we integrated the total current and fit the initial rise of the integral with an exponential. The rise was significantly faster for the middle molecular layer compared with the outer molecular layer $(3.5 \pm 0.4$ versus $5.3 \pm 0.4 \mathrm{~ms}, p \leq 0.01, n=5$, unpaired $t$ test,). A faster rising phase of the membrane potential is consistent with tighter coupling to spike generation (FitzHugh and Antosiewicz, 1959).

\section{Asynchronous stimulation of the perforant path recruits IPSCs in GCs but EPSCs in FS interneurons}

Our observation that FS interneurons are more strongly coupled to the perforant path than GCs begs the question: what are the relative sizes of the unitary synaptic strengths (the output of a single perforant path axon) onto FS interneurons versus GCs? To address this, we asynchronously stimulated the perforant path by pressure applying $100 \mathrm{~mm} \mathrm{KCl}$ to the far side of the hippocampal fissure, across from the molecular layer of the dentate gyrus. Importantly, this also allowed us to study the perforant path input in a context that is likely closer to the physiological input compared with driving the system synchronously with electrical shocks. Voltage-clamp responses recorded in GCs and FS interneurons showed a barrage of evoked EPSCs and IPSCs (Fig. $3 A, B$ ). By taking the mean of the median-evoked EPSC amplitude for each recording, we estimate that the evoked unitary current for perforant path to GCs was $21.3 \pm 1.7 \mathrm{pA}(1.4 \pm 0.1 \mathrm{pA} / \mathrm{pF})$, and that to FS interneurons was $35.7 \pm 4.3 \mathrm{pA}(1.6 \pm 0.2 \mathrm{pA} / \mathrm{pF})$. The evoked unitary current density was not significantly different between cell types ( $p \leq 0.37 n=5$, unpaired $t$ test). We took advantage of the moderate rate of spontaneous EPSCs in FS interneurons to show that there is no significant difference in the median peak amplitude of spontaneous versus evoked EPSCs ( $p \leq 0.14$ paired $t$ test, $n=5$ ), supporting our interpretation that these measurements are a good estimate for the unitary sizes.

It is possible that the puff stimulus might diffuse sufficiently to directly depolarize GCs in the network that are close to the stimulating pipette but far from the GC from which we are recording. Such recruitment could potentially lead to recruitment of GCmediated EPSCs in interneurons via the feedback pathway, thus confounding the above results. To test for this, we maximized the probability of direct activation of GCs and characterized the extent of puff-evoked activation over distance (supplemental Fig. 1, available at www.jneurosci.org). We found that under our stimulus conditions, the puff-evoked EPSCs are in fact arising from activation of perforant path fibers rather than a mix of perforant path fibers and GCs.

Assuming that the sizes of the unitary current densities are similar for medial and lateral perforant path synapses, 10 synchronously active fibers in the outer molecular layer would drive a GC to the midpoint of its input-output function, whereas only six would need to be synchronously active to drive a FS interneuron. For the middle molecular layer, 14 active fibers would drive a GC, whereas only five would be required to drive a FS interneuron. These results suggest that a small number of synchronously activated perforant path fibers would be able to preferentially recruit FS interneurons, as observed in our simultaneous recordings. Considering the smaller difference between the number of required fibers to recruit FS interneurons versus GCs for the lateral perforant path may account for why we saw no difference 
A
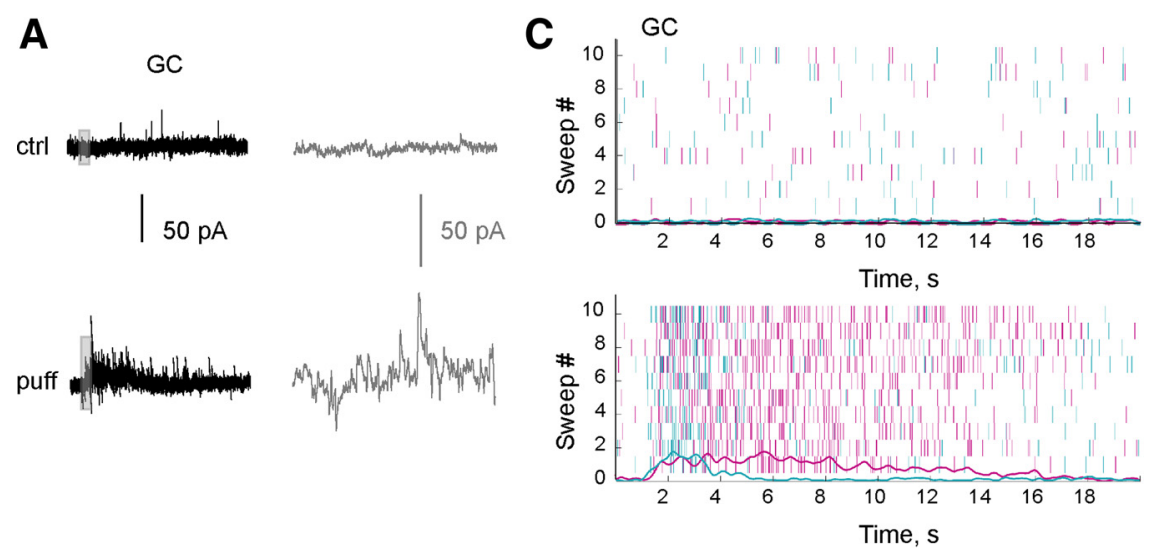

B
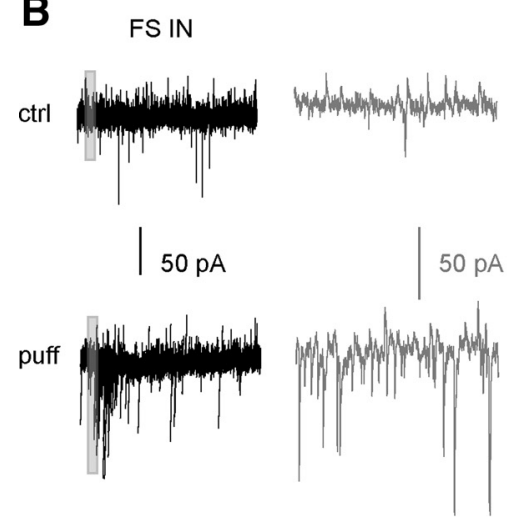

D
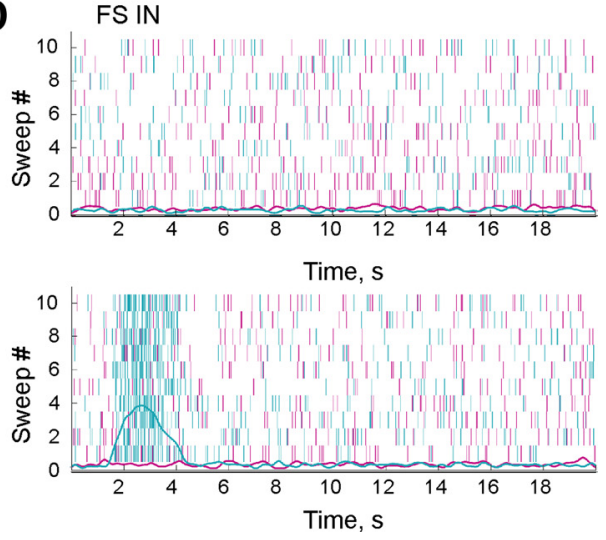

Figure 3. Puff activation of perforant path recruits mainly IPSCs in GCs and mainly EPSCs in FS interneurons. $A$, Twenty second voltage-clamp responses (black) of a GC clamped at $-40 \mathrm{mV}$ in control (ctrl) (top) and after puffing $100 \mathrm{~mm} \mathrm{KCl}$ to perforant path (bottom). Gray traces are $1 \mathrm{~s}$ of the trace enlarged to display individual IPSCS and EPSCS. B, Same as $\boldsymbol{A}$, but for a FS interneuron (FS IN). C, Rasters for recordings made in a GC in control trials (top) and puff trials (bottom) marking IPSC arrival times (magenta dashes) and EPSC arrival times (cyan dashes). Each row represents a separate trial. Magenta and cyan lines show smoothed counts for IPSCs (magenta) and EPSCS (cyan) across trials. Puff stimulus was delivered at time $=1$ s. D, Same as C, but for a FS IN.

in recruitment in the simultaneous recordings for the outer molecular layer stimulation (Fig. 1).

When both excitatory and inhibitory synaptic events were detected (see Materials and Methods), it was revealed that puff stimulation of the perforant path recruits mainly IPSCs in GCs, but mainly EPSCs in FS interneurons (Fig. 3C,D). In GCs, puff stimulation caused an increase in the rate of IPSCs from $3.2 \pm 0.7$ to $6.5 \pm 0.4 \mathrm{~Hz}(p \leq 0.004, n=9$, paired $t$ test $)$, and an increase in the rate of EPSCs from $1.8 \pm 0.5$ to $3.3 \pm 0.7 \mathrm{~Hz}(p \leq 0.0007$, $n=9$, paired $t$ test). The magnitude of the change in IPSC rate significantly outweighs that of the change in EPSC rate (unpaired $t$ test, $p \leq 0.047, n=9$ ), suggesting that despite receiving an excitatory input from the perforant path, GCs would undergo net shunting inhibition. In a subset of these experiments, a control was done to ensure that the increase in IPSCs was not caused by direct activation of GABAergic interneurons. Under the same recording and stimulus configuration, when $10 \mu \mathrm{M}$ DNQX (an AMPA receptor antagonist) was bath applied, the puff-evoked increase in IPSCs was completely abolished (supplemental Fig. 2, available at www.jneurosci.org). In FS interneurons, only the rate of EPSCs showed a significant increase from $6.9 \pm 2.3$ to $9.6 \pm 1.9$ $\mathrm{Hz}(p \leq 0.002, n=5$, paired $t$ test $)$, suggesting that an asynchronous perforant path drive would depolarize FS interneurons toward spike threshold. In half of the recordings the elevation in IPSC rate in GCs were sustained for several seconds, suggesting that late IPSCs arise from a source other than FS interneurons (Fig. 3C). It is possible that our puff stimulus was recruiting semilunar GCs, which recruit sustained spiking in hilar interneurons that may feed back onto the GCs that we were recording from (Larimer and Strowbridge, 2010). We also compared the magnitude of the puff-evoked increase of EPSC rate in FS interneurons and GCs. Interestingly, the increase in EPSC rate was larger in FS interneurons compared with GCs ( $p \leq$ 0.013, $n=5, n=9$, unpaired $t$ test), suggesting either that more fibers target them compared with GCs or that the release probability for the perforant path to FS interneuron synapses is higher than that for the perforant path to GC synapses. These results predict that asynchronous activity of the perforant path would preferentially recruit FS interneurons and result in a net inhibition of GCs in the dentate gyrus.

\section{Strong feedforward inhibition of GCs}

The input-output relationships (Fig. 2) revealed that it takes less synaptic current density to drive spikes in FS interneurons compared with GCs, but when current steps were injected directly to the soma (Fig. 1A), GCs required smaller current injections to fire spikes. This apparent paradox might be resolved by considering network effects rather than intrinsic membrane properties. The puff experiments suggest that synaptically driven responses in GCs are dominated by IPSCs, one source of which may be from perforant path recruitment of FS interneurons that synapse onto GCs (Kraushaar and Jonas, 2000; Bartos et al., 2001). Recruitment of inhibition could drastically change the coupling strength of the perforant path to GCs, as GCs would be integrating excitatory and inhibitory inputs, thus requiring larger excitation to reach spike threshold. We tested this by voltage clamping GCs at $-40 \mathrm{mV}$, roughly halfway between the reversal potentials of inhibitory and excitatory currents, and stimulating the middle molecular layer. We recorded a large IPSC that increased with stimulus intensity (Fig. $4 A$ ). The IPSC/EPSC ratios were plotted over a range of stimulus intensities and fit with a single exponential (Fig. 4C). As the stimulus intensity increased, the IPSC scaled up by a larger factor than the EPSC and reached a maximum of 3-fold higher, again suggesting that more perforant path fibers synapse onto GABAergic interneurons compared with GCs. This observation confirmed the presence of a large IPSC in GCs that would likely clamp GCs away from threshold, across all stimulus intensities. In contrast, much smaller IPSCs were recruited in FS interneurons and were overshadowed by a large EPSC regardless of stimulus intensity (Fig. 4B, C).

It is possible that the IPSCs recorded in GCs were recruited as a result of direct stimulation of the axons of GABAergic interneurons. If that were the case, the IPSC would not depend on excitatory synaptic transmission. However, the IPSC was reversibly blocked by $10 \mu \mathrm{M}$ DNQX, an AMPA receptor antagonist (Fig. $4 D$, left). The IPSC was reduced from $70 \pm 13 \mathrm{pA}$ in control to $8.6 \pm 2 \mathrm{pA}$ in drug and recovered to $45 \pm 9.8 \mathrm{pA}$ or $64 \%$ of control during wash (Fig. $4 D$, right). These results suggest that 
A

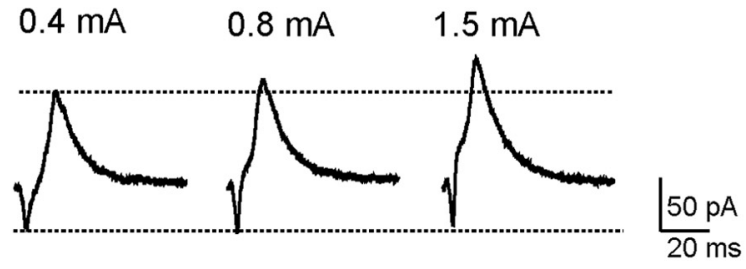

B

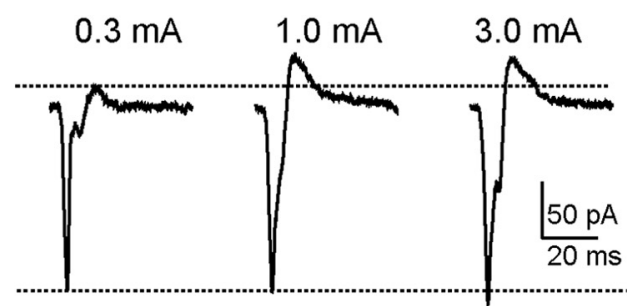

E

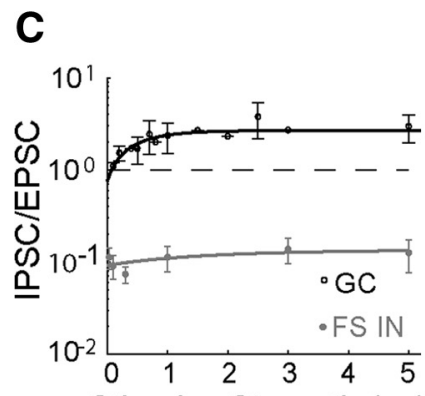

Stimulus Strength $(\mathrm{mA})$
D

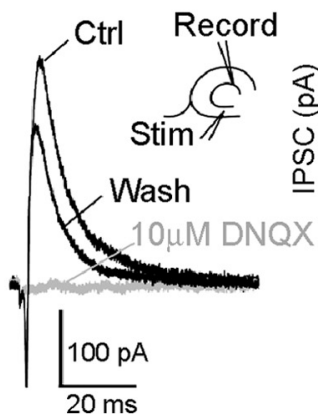

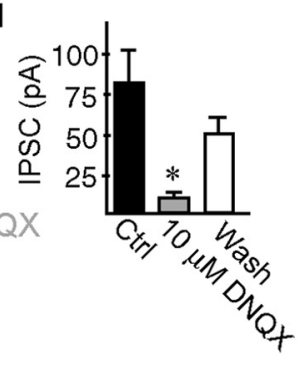

Figure 4. Perforant path recruits strong inhibition in $\mathrm{GCs}$ that occludes $\mathrm{GC}$ sensitivity to perforant path inputs. $A$, Voltage-clamp response of a $\mathrm{GC}$ clamped at $-40 \mathrm{mV}$ to a single pulse delivered to the middle molecular layer at varying stimulus strengths. $\boldsymbol{B}$, Same as $\boldsymbol{A}$ but for a FS interneuron (FS IN). C, The IPSC/EPSC ratio as a function of stimulus strength for GCS (black) and FS INs (gray). Dotted line shows where IPSC/EPSC $=1$. Ratios are significantly different for GCs compared with FS INs ( $p \leq 0.01, n=8$ for FS INs, $n=6$ for GCs, F test, see Materials and Methods). D, Voltage-clamp response of a GC clamped at $-40 \mathrm{mV}$ to a single pulse delivered to the middle molecular layer in control (Ctrl), $10 \mu \mathrm{m} \mathrm{DNQX}$, and wash conditions (left). IPSC amplitude is significantly reduced by $10 \mu \mathrm{m} \mathrm{DNQX} \mathrm{(right).} \mathrm{The} \mathrm{difference} \mathrm{in} \mathrm{amplitudes} \mathrm{was} \mathrm{significant} \mathrm{between} \mathrm{control} \mathrm{and} \mathrm{drug} \mathrm{conditions} \mathrm{but} \mathrm{not} \mathrm{between} \mathrm{control} \mathrm{and} \mathrm{wash} \mathrm{conditions} \mathrm{(} p \leq 0.01, n=7$, one-way ANOVA with repeated measures, Dunnett's test). Stim, Stimulus. E, Blocking inhibition reverses sensitivity of GCs and FS INs to perforant path inputs. Input- output curves for middle molecular layer (MML) fibers to GC and FS IN synapses (left) and outer molecular layer (OML) fiber synapses (right) in the presence of $5 \mu \mathrm{m}$ bicuculline and $1 \mu \mathrm{M}$ CGP55845. Compare with Figure 2 in absence of bicuculline and CGP55845.

the IPSCs were mediated by the feedforward pathway (perforant path to interneuron to GC); however, we cannot rule out some contribution by feedback pathways (perforant path to GC to interneuron to GC).

\section{Block of inhibition reveals strong coupling between perforant path and GCs}

Given our observation of strong feedforward inhibition in GCs, we reexamined the input-output relationships (Fig. 2) in the presence of $5 \mu \mathrm{M}$ bicuculline (a $\mathrm{GABA}_{\mathrm{A}}$ receptor antagonist) and $1 \mu \mathrm{M}$ CGP55845 (a GABA $\mathrm{B}$ receptor antagonist). By simply removing inhibition, the coupling strength between the perforant path and GCs was greatly increased, demonstrating that the sensitivity of GCs to their perforant path inputs is regulated by the presence of the large IPSC discussed above. The coupling strength of both pathways to GCs increased $\sim 3$-fold compared with control conditions as illustrated by a left shift of the inputoutput curve for GCs ( $p \leq 0.0002$ for middle molecular layer and $p \leq 0.004$ for outer molecular layer, unpaired $t$ test) (Fig. $4 E$, compare with Fig. $2 B$ ). With inhibition blocked, the midpoint of the input-output curve for the middle molecular layer fibers was smaller for GCs $[5.6 \pm 0.28 \mathrm{pA} / \mathrm{pF}(102 \pm 14 \mathrm{pA})]$ compared with FS interneurons $[13 \pm 2.2 \mathrm{pA} / \mathrm{pF}(355 \pm 61 \mathrm{pA})](p \leq 0.05, n=$ $5, n=6$, unpaired $t$ test) (Fig. $4 E$, left). This was also the case for outer molecular layer fibers For GCs, the midpoint was $5.4 \pm 0.6$ $\mathrm{pA} / \mathrm{pF}(98 \pm 7 \mathrm{pA})$ whereas for FS interneurons it was $13 \pm 2.7$ $\mathrm{pA} / \mathrm{pF}(347 \pm 68 \mathrm{pA})(p \leq 0.05, n=5, n=6$, unpaired $t$ test $)$ (Fig. $4 E$, right). Unlike GCs, FS interneurons did not exhibit changes in coupling strength in either pathway when inhibition was blocked ( $p \leq 0.06$ for MML and $p \leq 0.23$ for OML, unpaired $t$ test). This was not surprising given the small magnitude of the IPSCs recruited in FS interneurons (Fig. 4B).

\section{FS interneurons display frequency dependence to perforant path input}

In the dentate gyrus, FS interneurons are known to participate in oscillations that are driven by oscillations in the entorhinal cortex (Chrobak and Buzsaki, 1998). Therefore, it is important to consider the effect of the frequency of perforant path inputs on the strong recruitment of FS interneurons. Thus far, all results were obtained for a single stimulus frequency $(10 \mathrm{~Hz})$ at room temperature. To test the dynamics of the recruitment of GCs and FS interneurons, we obtained simultaneous current-clamp recordings from GCs and FS interneurons at physiological temperature for 5 and $10 \mathrm{~Hz}$ stimulus trains delivered to the outer molecular layer (Fig. $5 A, B$, compare with Fig. $1 C, D$ ). Confirming our previous result at room temperature, the perforant path showed a strong preference for recruitment of FS interneurons over GCs, but at physiological temperature this preference was even stronger, with GCs failing to fire spikes entirely. At $5 \mathrm{~Hz}$ the average number of spikes recruited in the FS interneurons was $33.23 \pm$ 10.06 , and for $10 \mathrm{~Hz}$ it was $42.63 \pm 9.48$ ( $n=4$ pairs). For both cases the number of spikes exceeded the number of stimuli in the train (20), meaning that some stimuli in the train evoked more than one spike. These results were observed for both outer molecular and middle molecular layer stimulation sites (data not shown for middle molecular layer); however, to study the bursting mechanism we decided to focus on just the outer molecular layer stimulation site, as it is less likely that our stimulus would be directly activating commissural and mossy cell fibers.

It is possible that our observation that the perforant path preferentially recruits FS interneurons and recruits bursts in FS interneurons is dependent on the internal solutions that we are using. To test this, we reproduced these results using the less invasive cell-attached recording mode. Of the eight putative FS interneu- 
A
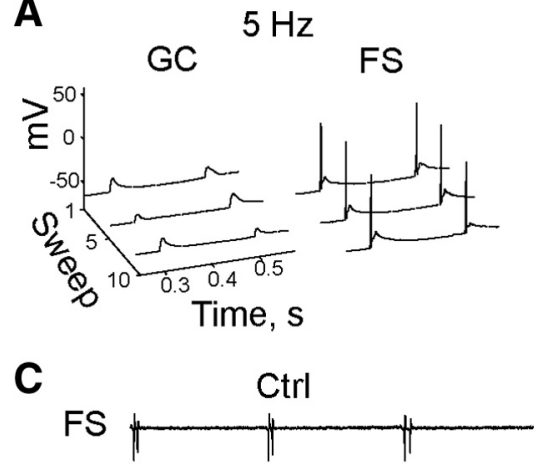

GC
B

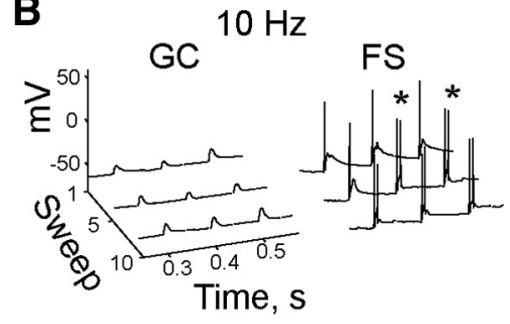

$10 \mu \mathrm{M}$ Bicuculline
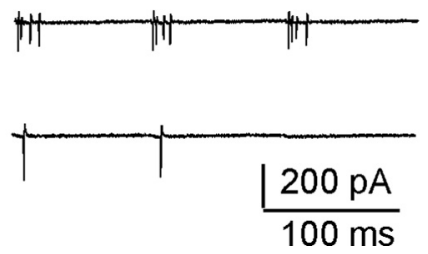

Figure 5. Perforant path preferentially recruits FS interneurons at physiological temperature and in cell-attached mode. $A$, Five hundred millisecond clips of simultaneously recorded current-clamp responses of a $\mathrm{GC}$ (left) and a FS interneuron (right) to a $5 \mathrm{~Hz}$ stimulus train delivered to the outer molecular layer at $35^{\circ}$. $\boldsymbol{B}$, Same as $\boldsymbol{A}$, but for $10 \mathrm{~Hz}$. Significantly more spikes were recruited in FS interneurons compared with $\mathrm{GCS}$ ( $p \leq 0.021, n=4$, paired $t$ test). Asterisks mark recruited doublets. C, Simultaneously recorded cell-attached responses of FS (top) and GC (bottom) in control conditions (left) and $10 \mu \mathrm{m}$ bicuculline (right) to $10 \mathrm{~Hz}$ stimulus train delivered to the outer molecular layer. Significantly more spikes were recruited in FS INs compared with GCS ( $p \leq$ 0.008 , paired $t$ test, $n=6$ pairs). Note that FS INs fire bursts for perforant path input in both whole-cell and cell-attached recording modes.

rons recorded in this mode, five of them showed the recruitment of bursts upon stimulation of the outer molecular layer with a 10 $\mathrm{Hz}, 20$ pulse stimulus train. For six of these recordings we were able to simultaneously record from an interneuron and a putative granule cell (Fig. 5C, left). In all cases, perforant path stimulation recruited more spikes per stimulus train in interneurons $(22.2 \pm$ 5.2) compared with granule cells $(0.08 \pm 0.08)$ ( $p \leq 0.008$, paired $t$ test, $n=6$ pairs), supporting the results obtained in the wholecell mode. To test whether GABA is mediating an inhibitory effect in GCs under the conditions of our experiments, in two of the paired recordings we were able to successfully wash on $10 \mu \mathrm{M}$ bicuculline, which resulted in recruitment of spikes in GCs (Fig. $5 C$, right). Furthermore, we additionally recorded from seven GCs under conditions of maximal perforant path stimulation in control and $10 \mu \mathrm{M}$ bicuculline conditions. Under control conditions, GCs fired few spikes per stimulus train $(0.5 \pm 0.27)$ and increased firing upon bath application of $10 \mu \mathrm{M}$ bicuculline $(7.3 \pm 1.3)(p \leq 0.0004$, paired $t$ test, $n=9)$, suggesting that, as expected, $\mathrm{GABA}_{\mathrm{A}}$ receptors mediate an inhibitory effect in GCs that occludes GC sensitivity to perforant path inputs. Qualitatively, these results support our previous findings observed in the whole-cell mode; however, it does seem that the whole-cell mode slightly underestimates GC spiking in response to stimulation of perforant path inputs (i.e., 5/9 GCs showed some spiking in control conditions in the cell-attached mode, whereas none did in the whole-cell mode).

Bursts have been reported in certain classes of FS interneurons in vitro previously (Buhl et al., 1994; Hajos et al., 2004); however, the frequency dependence of burst recruitment has not yet been explored. Observing that the $10 \mathrm{~Hz}$ train recruited more bursts in FS interneurons compared with the $5 \mathrm{~Hz}$ train, an expanded range of stimulus frequencies was tested to see whether certain frequency inputs would preferentially promote bursts. Currentclamp responses to $20 \mathrm{~s} 1,3,10$, and $30 \mathrm{~Hz}$ stimulus trains were recorded (Fig. $6 A-D$ ). Compared with the $1 \mathrm{~Hz}$ train (treated as a control), the $10 \mathrm{~Hz}$ train was most efficient at recruiting bursts with an average number of $1.8 \pm 0.2$ spikes per stimulus compared with the 3 $\mathrm{Hz}$ train $(1.4 \pm 0.2)$ and the $30 \mathrm{~Hz}$ train $(1.3 \pm 0.1), n=11$. All values were compared with the $1 \mathrm{~Hz}$ condition that almost always produced just one spike per stimulus. Only the $10 \mathrm{~Hz}$ condition evoked significantly more spikes per burst $(p \leq$ $0.01, n=11$, one-way ANOVA with repeated measures), suggesting that the burst recruitment in FS interneurons is tuned to perforant path signals arriving at $\sim 10 \mathrm{~Hz}$ (Fig. 6E). These results confirm that the frequency of the perforant path input regulates FS interneuron response profiles and preferentially recruits bursting within the theta frequency range.

\section{Bursts in FS interneurons are driven by multisynaptic input}

Several possibilities could account for why $10 \mathrm{~Hz}$ signals promote bursts in FS interneurons. As a first step, the underlying currents were measured to shed light on a mechanism for bursting. Stimulating the outer molecular layer at $10 \mathrm{~Hz}$ and recording the EPSC responses in a FS interneuron revealed multisynaptic currents as seen at room temperature (Fig. $7 A$, top, compare with Fig. $2 A$, inset). At physiological temperature, the multisynaptic nature of the currents was even more dramatic. In each response, several EPSCs overlay each other staggered in time, which is visualized as lumpiness in the EPSCs. To test whether the later components of the multisynaptic event were sufficient to drive the later spikes in a burst, we injected the EPSC patterns back into the soma via the recording pipette, which effectively drove bursts (Fig. $7 A$, bottom) in $8 / 8 \mathrm{FS}$ interneurons, suggesting that the dendritic location of synaptic input is not critical for bursting. The input was aligned to individual spike times, and individual EPSCs were detected as threshold crossings of the time derivative of injected current above $2 \times$ its standard deviation. Identified EPSCs preceded each spike in the burst by $2.06 \pm 0.23 \mathrm{~ms}$ (Fig. $7 B$ ). This result suggests that the multisynaptic input is key to bursting and that the later spikes are driven by delayed EPSPs rather than by a burst mechanism intrinsic to the cell.

\section{The feedback pathway mediated by GCs underlies late EPSPs that drive bursts in FS interneurons}

There are several possible sources for the late EPSPs that drive bursts in FS interneurons. Given the existence of a back projection from area CA3 (Scharfman, 2007) and the possibility that we are recruiting CA3 pyramidal cells with our stimulus, we tested whether bursts in FS interneurons require CA3. This was done by cutting off area CA3 and then recording the response of FS interneurons to a $10 \mathrm{~Hz}$ stimulus train delivered to the outer molecular layer. In $4 / 4$ slices tested, we were able to record bursts in slices that no longer had area $\mathrm{CA} 3$, ruling out the back projection as the synaptic source driving the later spikes in the burst (Fig. $7 C, D$ ). Two of these slices had virtually no hilus and were composed of just the GC layer and molecular layer (even the upper and lower blades of the GC layer were removed), discounting hilar mossy cells as the source of the late EPSPs. This leaves GCs as the most likely candidate, as they receive input from the perforant path 
and are known to make very powerful unitary contacts with FS interneurons (Geiger et al., 1997). However, we rarely observed perforant path-evoked spikes in GCs (in the cell attached mode 5/9 GCs fired $\sim 1$ spike per train), possibly because GC spiking is sparse and difficult to detect in a limited sample. FS interneurons, in contrast, sample inputs from a large number of GCs, raising the possibility that the late spikes report the sparse activity of even a few GCs. To test this we exploited the observation that terminals of GCs express metabotropic glutamate type II receptors (mGluRII) that suppress synaptic release (Doherty and Dingledine, 1998; Doherty et al., 2004). We stimulated the outer molecular layer with a $10 \mathrm{~Hz}$ train and recorded the resulting currents and burst patterns in FS interneurons (Fig. $7 E)$. The same train was delivered while simultaneously puffing $5 \mu \mathrm{M}$ DCG-IV (a mGluRII agonist) on the hilar side of the FS interneuron dendrites, where GC terminals synapse. Local puff application was used because perforant path synaptic terminals also express mGluRIIs (Macek et al., 1996); therefore, bath application would be expected to abolish the entire response. Application of DCG-IV reversibly blocked the late EPSCs and reversibly reduced the mean probability of bursting from $0.7 \pm 0.12$ to $0.004 \pm 0.004(n=5)$ while leaving the initial spike intact, suggesting that late spikes in bursts arise from activation of GCs (Fig. 7F).

If GCs are responsible for late spikes in FS interneuron bursts, then we would expect that the perforant path recruitment of GCs would show frequency dependence, because the presence of bursts shows frequency dependence. To explore this, we exploited our earlier result that GCs are tightly suppressed by inhibition, but when inhibition is blocked they become very sensitive to perforant path input. We therefore bath applied $1 \mu \mathrm{M}$ bicuculline $\left(\sim \mathrm{EC}_{50}\right)$ (Jones et al., 2001), and recorded the current-clamp response of GCs to trains of 20 stimuli at $1,3,10$, and $30 \mathrm{~Hz}$ (Fig. 8). The average number of spikes per stimulus train as a function of frequency followed the same distribution as the frequency-dependent burst recruitment in FS interneurons (compare with Fig. $6 E$ ). The train recruited on average $3.3 \pm 1.2$ spikes for $1 \mathrm{~Hz}, 4.3 \pm 1.2$ spikes for $3 \mathrm{~Hz}, 7.1 \pm 2$ spikes for $10 \mathrm{~Hz}$, and $3.5 \pm 1$ spikes for $30 \mathrm{~Hz}$. Compared with the $1 \mathrm{~Hz}$ condition (treated as control), only the $10 \mathrm{~Hz}$ condition recruited more spikes ( $p \leq 0.02, n=7$, one-way ANOVA with repeated measure Dunnett's test). This is direct evidence that GCs can be recruited by the perforant path in a frequencydependent manner; however, only GCs that have a lower magnitude of inhibition, mimicked in this case by bicuculline, may show this frequency dependence. Together, the results above suggest that the first spike in a burst reflects the timing of perforant path activity (the feedforward pathway), and the later spikes re-

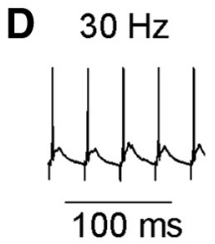
Dunnett's test, $n=11)$.
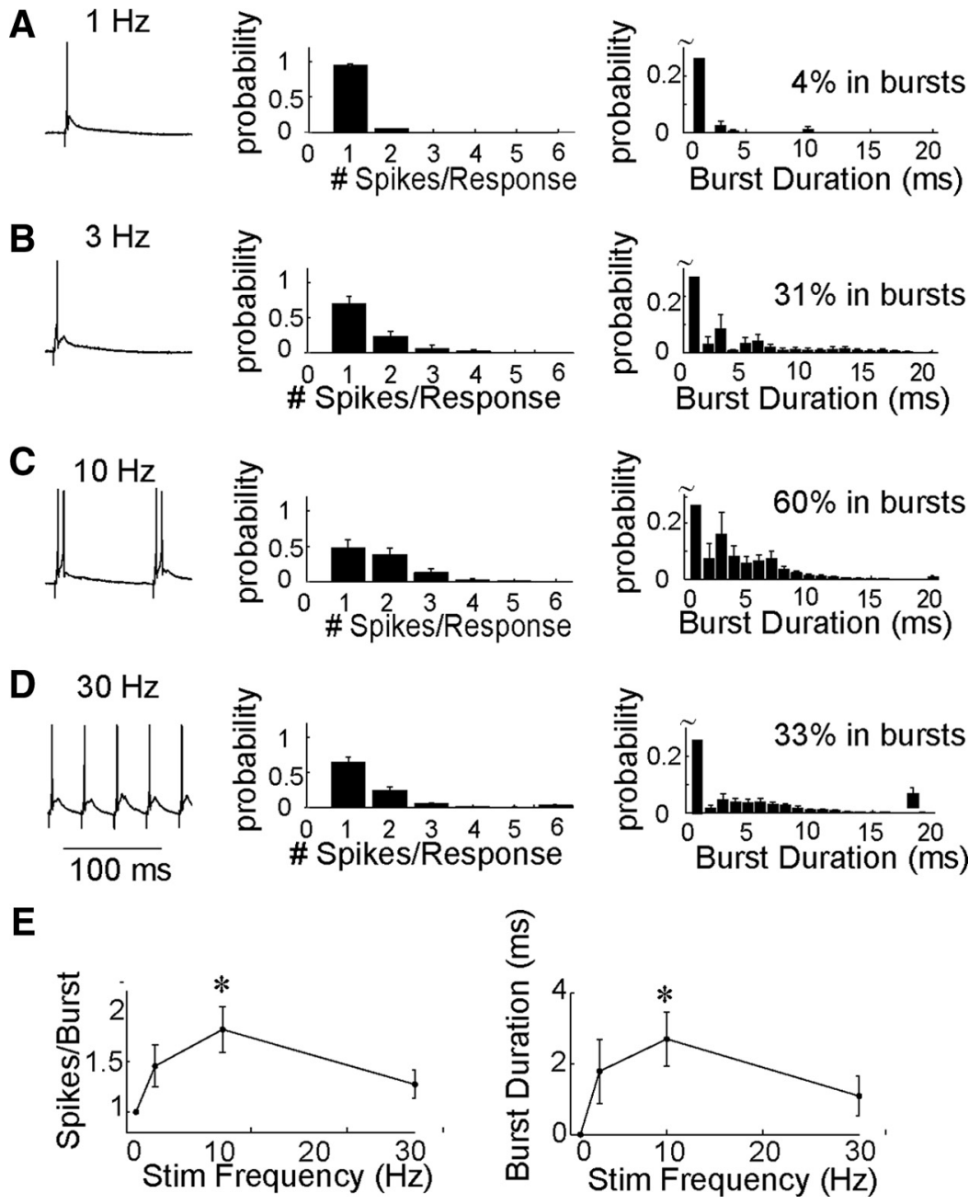

Figure 6. FS interneurons respond in a frequency-dependent manner to perforant path input. $\boldsymbol{A}$, Left, Clip of currentclamp response of a FS IN to $1 \mathrm{~Hz}, 20$ s stimulus train delivered to the lateral perforant path at $35^{\circ}$. Middle, The probability 列 $10 \mathrm{~Hz}$ stimulus recruited significantly more bursts ( $p \leq 0.01$ right, $p \leq 0.01$ left, one-way ANOVA with repeated measures,

flect the timing of GC activity (the feedback pathway). We do not differentiate between GCs and semilunar GCs, and therefore the feedback pathway may be a mixture of these two cell types.

\section{Discussion}

In summary, our results show that the perforant path preferentially inhibits dentate gyrus output primarily by recruiting inhibitory interneurons. FS interneurons receive a strong excitatory drive from the perforant path that effectively drives spikes. The increased activity in FS interneurons, and probably other inhibitory interneurons, confers a large feedforward inhibitory conductance in GCs. Even though GCs also receive perforant path excitatory input and are actually very strongly coupled to that input, the inhibition dominates and GCs are effectively suppressed. However, FS interneurons fire GC-driven bursts for certain frequencies of perforant path input, suggesting that the temporal pattern of activity in entorhinal cortex shapes the amount and timing of inhibition and excitation in the dentate 
A Input

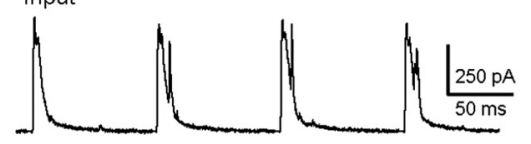

Output

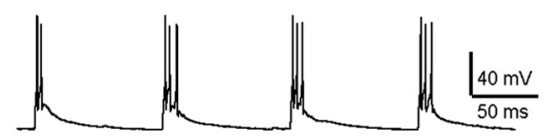

B

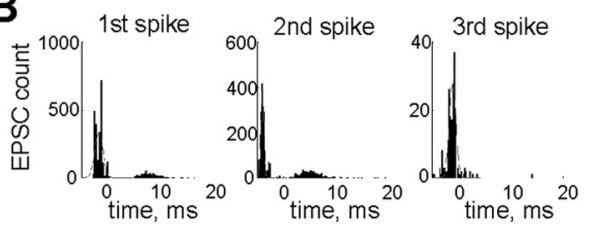

C

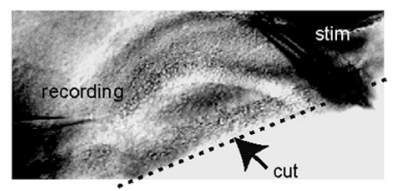

D
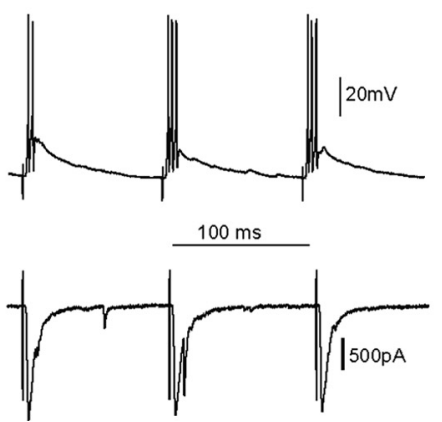

E

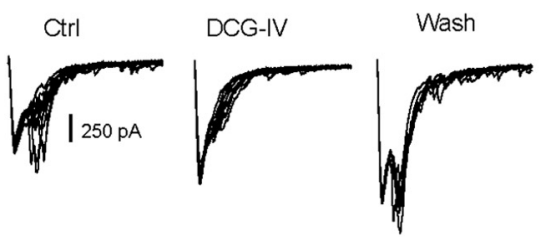

$\mathbf{F}$
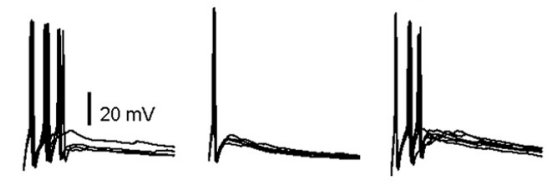

Figure 7. Each spike in a FS interneuron burst is driven by a distinct EPSC. $\boldsymbol{A}$, Multisynaptic current input injected to the soma of the FS interneuron elicits bursts at $35^{\circ}$. Top, Input generated by converting a voltage-clamp response recorded in the same FS interneuron into a current command. Bottom, Burst response of a FS interneuron to the above input. $\boldsymbol{B}$, Histogram of number of EPSCs that preceded the first spike in a burst (left), the second spike (middle), and the third spike (right) in a burst. Time 0 is the time of the spike. On average, EPSCs precede spikes by $2.06 \pm 0.23 \mathrm{~ms}(n=8)$. C, Visualization of a slice under IR-DIC optics where CA3 has been cut off. $D, 0$ uter molecular layer stimulation-recruited bursts (top) and multisynaptic currents (bottom) are still present in FS interneuron of a slice that has had CA3 removed ( $n=4 / 4$ slices). $E$, Late EPSCs and spikes in FS interneurons are blocked by type II metabotropic glutamate receceptor agonist. Overlaid $40 \mathrm{~ms}$ clips of the current (top) and voltage (bottom) responses of a FS interneuron to a $10 \mathrm{~Hz}$ stimulus train delivered to the outer molecular layer in control (Ctrl), $5 \mu \mathrm{m}$ DCG-IV, and wash show block and recovery of late EPSCs and bursts. $\boldsymbol{F}$, The probability of bursts is significantly lower in the presence of DCG-IV compared with control and wash conditions ( $p \leq 0.01$, one-way ANOVA with repeated measures, Dunnett's test, $n=5$ ).

A

B

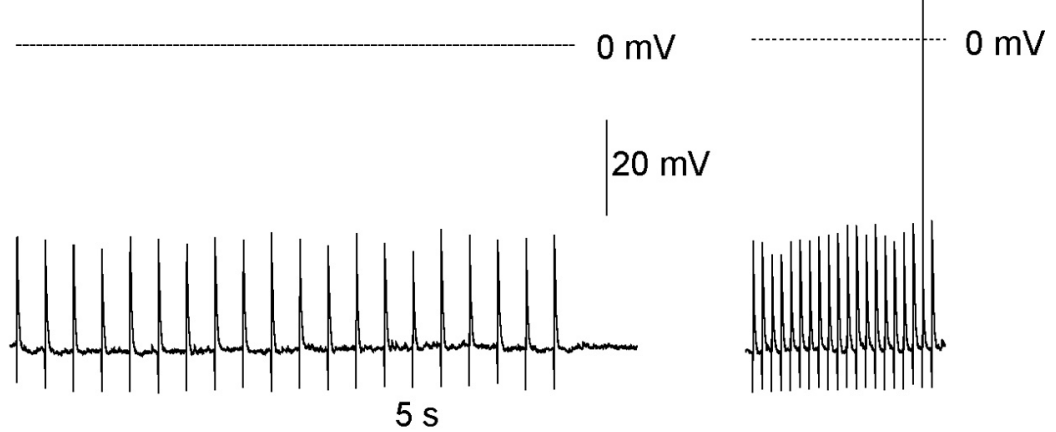

C

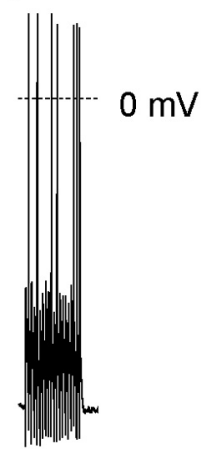

D

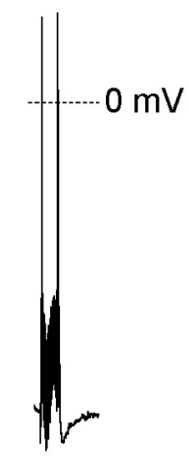

E

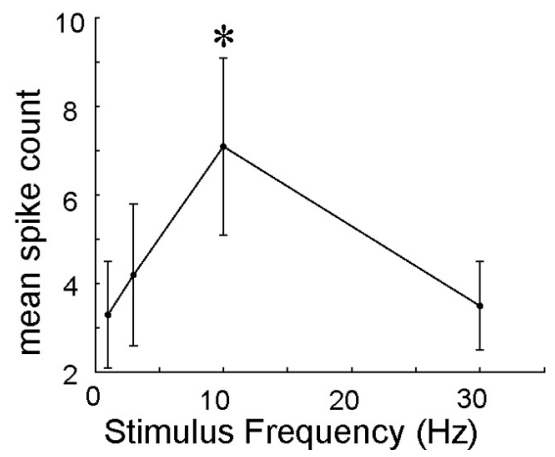

Figure 8. $\mathrm{GCS}$ respond in a frequency-dependent manner to perforant path input under conditions where inhibition is partially blocked. $\boldsymbol{A}$, Current-clamp response of a $\mathrm{GC}$ to a $1 \mathrm{~Hz}$ train delivered to the outer molecular layer in $10 \mu \mathrm{M}$ bicuculline at $35^{\circ}$. Note the presence of subthreshold EPSCs but no spikes. $\boldsymbol{B}$, Response of the same cell to a $3 \mathrm{~Hz}$ train where one spike was recruited. $\boldsymbol{C}$, Same as $\boldsymbol{B}$, but for $10 \mathrm{~Hz}$. D, Same as $\boldsymbol{B}$, but for $30 \mathrm{~Hz}$. $\boldsymbol{E}$, The $10 \mathrm{~Hz}$ stimulus condition was the only condition that recruited significantly more spikes per train than the $1 \mathrm{~Hz}$ condition, which was treated as a control ( $p \leq 0.02$, one-way ANOVA with repeated measures, Dunnett's test, $n=7$ ).

gyrus such that GCs become more active at frequencies near theta.

Lateral versus medial perforant path

When constructing input-output relationships, care was taken to differentially stimulate the outer molecular layer (lateral perforant path) versus the middle molecular layer (medial perforant path). This was done because these pathways arise from distinct regions of the entorhinal cortex and code different types of information (Witter, 2007). In FS interneurons the medial perforant path required less current density to drive spiking than did the lateral perforant path. This is likely caused by a faster rising time of the EPSP recruited by the medial perforant path, which undergoes less dendritic filtering because the location of this pathway is more proximal compared with the lateral perforant path inputs. We expect that dendritic filtering would not affect EPSPs in GCs as much, because GCs are more electrotonically compact (SchmidtHieber et al., 2007). This result suggests that the medial perforant path is especially good at recruiting feedforward inhibition and suppressing the activity of GCs and, hence, dentate gyrus output. This is particularly interesting when considering that the medial perforant path may carry redundant signals already "seen" by the hippocampus, whereas the lateral perforant path carries signals about novelty (Biella and de Curtis, 2000). Perhaps the ability of the medial perforant path to recruit strong feedfor- 
ward inhibition is necessary for the dentate gyrus to "filter" redundant information out before sending signals to downstream hippocampal areas.

\section{Frequency-tuned inhibition}

The dentate gyrus has been proposed to act as a pattern separator to downstream hippocampal areas (Leutgeb et al., 2007), based in part on the sparse firing of GCs (O'Reilly and McClelland, 1994) that is likely achieved through inhibition. Because the coupling strength of GCs to the perforant path is regulated by synaptic inhibition, conditions of decreased inhibition should liberate GCs and allow them to respond to their perforant path inputs. This may occur in cases of frequency-dependent synaptic depression (Kraushaar and Jonas, 2000) and during state-dependent neuromodulation that suppresses inhibition (Freund and Gulyas, 1997).

It has been shown in organotopic slices that net inhibition in CA3 pyramidal cells can be switched to net excitation in a frequency-dependent manner (Mori et al., 2004). The switch is mediated by facilitation of EPSPs and depression of IPSPs, both of which are frequency dependent and together confer net excitation at high frequencies. In our hands something similar may be happening at $10 \mathrm{~Hz}$, evident by bursts recorded in FS interneurons that report GC activity in the network. We imagine that below $10 \mathrm{~Hz}$ inhibition dominates. For stimuli arriving near 10 $\mathrm{Hz}$, inhibition may be more depressed than excitation, allowing the perforant path to effectively drive GCs. At higher frequencies, however, depression of excitation may render the drive insufficient once more.

\section{Network implications of bursting}

Frequencies near the theta range $(5-10 \mathrm{~Hz})$ (Bragin et al., 1995) were best at recruiting bursts in FS interneurons, suggesting that physiologically relevant firing patterns of entorhinal cortex cells would be best at recruiting GCs and thus bursts in FS interneurons. At the network level, bursting in interneurons has been suggested to be important in synchronizing network oscillations across large distances (Bibbig et al., 2002), where the interval between spikes in the burst encodes the phase difference between two spatially distinct oscillators. Here, we have presented evidence that the first spike in a FS interneuron burst encodes the timing of perforant path input, whereas the later spikes encode the timing of GC spikes. Consider perforant path inputs arriving near theta frequency that activate GCs sparsely and with different conduction delays. The firing of an individual GC drives a burst in a FS interneuron, which in turn broadcasts information about the timing of that GC, in the form of an IPSP, to all other GCs under its influence. That IPSP may cause phase advances or phase delays depending on its size, the phase of activity in the target GCs, and their biophysical properties. These effects could contribute to synchronizing or desynchronizing activity across the population (Bibbig et al., 2002; Merriam et al., 2005). Such a desynchronizing role might contribute to pattern separation by allowing multiple patterns to coexist by preventing their overlap in the temporal domain (Izhikevich, 2007).

\section{References}

Abraham WC, McNaughton N (1984) Differences in synaptic transmission between medial and lateral components of the perforant path. Brain Res 303:251-260.

Bartos M, Vida I, Frotscher M, Geiger JR, Jonas P (2001) Rapid signaling at inhibitory synapses in a dentate gyrus interneuron network. J Neurosci 21:2687-2698.

Bartos M, Vida I, Frotscher M, Meyer A, Monyer H, Geiger JR, Jonas P
(2002) Fast synaptic inhibition promotes synchronized gamma oscillations in hippocampal interneuron networks. Proc Natl Acad Sci U S A 99:13222-13227.

Bibbig A, Traub RD, Whittington MA (2002) Long-range synchronization of gamma and beta oscillations and the plasticity of excitatory and inhibitory synapses: a network model. J Neurophysiol 88:1634-1654.

Biella G, de Curtis M (2000) Olfactory inputs activate the medial entorhinal cortex via the hippocampus. J Neurophysiol 83:1924-1931.

Bragin A, Jandó G, Nádasdy Z, Hetke J, Wise K, Buzsáki G (1995) Gamma $(40-100 \mathrm{~Hz})$ oscillation in the hippocampus of the behaving rat. J Neurosci 15:47-60.

Buhl EH, Han ZS, Lörinczi Z, Stezhka VV, Karnup SV, Somogyi P (1994) Physiological properties of anatomically identified axo-axonic cells in the rat hippocampus. J Neurophysiol 71:1289-1307.

Chrobak JJ, Buzsáki G (1998) Gamma oscillations in the entorhinal cortex of the freely behaving rat. J Neurosci 18:388-398.

Doherty J, Dingledine R (1998) Differential regulation of synaptic inputs to dentate hilar border interneurons by metabotropic glutamate receptors. J Neurophysiol 79:2903-2910.

Doherty JJ, Alagarsamy S, Bough KJ, Conn PJ, Dingledine R, Mott DD (2004) Metabotropic glutamate receptors modulate feedback inhibition in a developmentally regulated manner in rat dentate gyrus. J Physiol 561:395-401.

FitzHugh R, Antosiewicz HA (1959) Automatic computation of nerve excitation - detailed corrections and additions. J Soc Indust Appl Math 7:447-458.

Freund TF, Buzsáki G (1996) Interneurons of the hippocampus. Hippocampus 6:347-470.

Freund TF, Gulyás AI (1997) Inhibitory control of GABAergic interneurons in the hippocampus. Can J Physiol Pharmacol 75:479-487.

Geiger JR, Lübke J, Roth A, Frotscher M, Jonas P (1997) Submillisecond AMPA receptor-mediated signaling at a principal neuron-interneuron synapse. Neuron 18:1009-1023.

Hájos N, Pálhalmi J, Mann EO, Németh B, Paulsen O, Freund TF (2004) Spike timing of distinct types of GABAergic interneuron during hippocampal gamma oscillations in vitro. J Neurosci 24:9127-9137.

Harney SC, Jones MV (2002) Pre- and postsynaptic properties of somatic and dendritic inhibition in dentate gyrus. Neuropharmacology 43:584-594.

Heinemann U, Beck H, Dreier JP, Ficker E, Stabel J, Zhang CL (1992) The dentate gyrus as a regulated gate for the propagation of epileptiform activity. Epilepsy Res Suppl 7:273-280.

Hu H, Martina M, Jonas P (2010) Dendritic mechanisms underlying rapid synaptic activation of fast-spiking hippocampal interneurons. Science 327:52-58.

Izhikevich EM (2007) Dynamical systems in neuroscience: the geometry of excitability and bursting. Cambridge, MA: MIT.

Jones MV, Jonas P, Sahara Y, Westbrook GL (2001) Microscopic kinetics and energetics distinguish $\mathrm{GABA}(\mathrm{A})$ receptor agonists from antagonists. Biophys J 81:2660-2670.

Kneisler TB, Dingledine R (1995) Spontaneous and synaptic input from granule cells and the perforant path to dentate basket cells in the rat hippocampus. Hippocampus 5:151-164.

Kraushaar U, Jonas P (2000) Efficacy and stability of quantal GABA release at a hippocampal interneuron-principal neuron synapse. J Neurosci 20:5594-5607.

Larimer P, Strowbridge BW (2010) Representing information in cell assemblies: persistent activity mediated by semilunar granule cells. Nat Neurosci 13:213-222.

Leutgeb JK, Moser EI (2007) Enigmas of the dentate gyrus. Neuron 55:176-178.

Leutgeb JK, Leutgeb S, Moser MB, Moser EI (2007) Pattern separation in the dentate gyrus and CA3 of the hippocampus. Science 315:961-966.

Liu X, Tilwalli S, Ye G, Lio PA, Pasternak JF, Trommer BL (2000) Morphologic and electrophysiologic maturation in developing dentate gyrus granule cells. Brain Res 856:202-212.

Lothman EW, Bertram EH 3rd, Stringer JL (1991) Functional anatomy of hippocampal seizures. Prog Neurobiol 37:1-82.

Macek TA, Winder DG, Gereau RW 4th, Ladd CO, Conn PJ (1996) Differential involvement of group II and group III mGluRs as autoreceptors at lateral and medial perforant path synapses. J Neurophysiol 76:3798-3806. 
Marr D (1971) Simple memory: a theory for archicortex. Philos Trans R Soc Lond B Biol Sci 262:23-81.

McNaughton BL (1980) Evidence for two physiologically distinct perforant pathways to the fascia dentata. Brain Res 199:1-19.

McNaughton BL, Barnes CA (1977) Physiological identification and analysis of dentate granule cell responses to stimulation of the medial and lateral perforant pathways in the rat. J Comp Neurol 175:439-454.

Merriam EB, Netoff TI, Banks MI (2005) Bistable network behavior of layer I interneurons in auditory cortex. J Neurosci 25:6175-6186.

Mori M, Abegg MH, Gähwiler BH, Gerber U (2004) A frequency-dependent switch from inhibition to excitation in a hippocampal unitary circuit. Nature 431:453-456.

Motulsky HJ, Ransnas LA (1987) Fitting curves to data using nonlinear regression: a practical and nonmathematical review. FASEB J 1:365-374.

Myers CE, Scharfman HE (2009) A role for hilar cells in pattern separation in the dentate gyrus: a computational approach. Hippocampus 19:321-337.
O’Reilly RC, McClelland JL (1994) Hippocampal conjunctive encoding, storage, and recall: avoiding a trade-off. Hippocampus 4:661-682.

Rolls ET (2007) An attractor network in the hippocampus: theory and neurophysiology. Learn Mem 14:714-731.

Scharfman HE (1991) Dentate hilar cells with dendrites in the molecular layer have lower thresholds for synaptic activation by perforant path than granule cells. J Neurosci 11:1660-1673.

Scharfman HE (2007) The CA3 "backprojection" to the dentate gyrus. Prog Brain Res 163:627-637.

Schmidt-Hieber C, Jonas P, Bischofberger J (2007) Subthreshold dendritic signal processing and coincidence detection in dentate gyrus granule cells. J Neurosci 27:8430-8441.

Witter MP (1993) Organization of the entorhinal-hippocampal system: a review of current anatomical data. Hippocampus 3 lsqb]Spec No]: 33-44. Witter MP (2007) The perforant path: projections from the entorhinal cortex to the dentate gyrus. Prog Brain Res 163:43-61. 